\title{
Energy expenditure in office workers with identified health risks
}

\author{
Yoganathan Coopoo (D Phil, FACSM) \\ Demitri Constantinou (MB BCh, BSc Med Hons, FFIMS) \\ Alan D Rothberg (MB BCh, FCPaed, PhD) \\ Centre for Exercise Science and Sports Medicine, School of Therapeutic Sciences, Faculty of Health Sciences, University of the \\ Witwatersrand, Johannesburg
}

\begin{abstract}
Objective. To measure the daily energy expenditure in employees previously identified as having $\geq 2$ risk factors for chronic disease, and to identify potential risk-reducing interventions for implementation within or outside the workplace.

Design. A total of 122 employees with $\geq 2$ risk factors for chronic disease identified in an in-house screening programme were invited to participate in a 6-month health management programme. Physical assessments included anthropometric measurements, blood pressure, blood glucose and cholesterol estimations, and bicycle ergometry. Participants were invited to wear a 'metabolic armband' (Body Media SenseWear Pro Armband®) for 6 days. Metabolic measures included active and total energy expenditure (AEE, TEE), and daily MET levels (metabolic equivalents expressed as $\mathrm{kcal} / \mathrm{kg} / \mathrm{hour}$ ). Differences were explored between genders, and relationships sought between energy expenditure, lifestyle and anthropometric data.
\end{abstract}

Setting. A corporate working environment. All measures and assessments were carried out in the in-house fitness facility.

Interventions. The health management programme involved physical assessments and personalised weight and activity management plans.

Main outcome measures. TEE per day, duration and quantification of physical activity, METS, AEE, number of steps per day and body position recording. Relationships were explored between the latter and anthropometric measures such as body mass index (BMI) and percentage body fat.

Result. Altogether $53(43 \%)$ of the eligible subjects volunteered for the 6-month programme and 49 enrolled for the metabolic armband study. The males were more active than the females, but both had BMI and body fat estimates that categorised them as overweight to obese. METS and AEE were positively correlated with duration of exercise rather than intensity, and negatively correlated with BMI. In a stepwise regression analysis for the total group $77 \%$ of the variance in MET levels was accounted for

\section{CORRESPONDENCE:}

Professor Y Coopoo

Medical School

Wits

2050

E-mail: yoga.coopoo@wits.ac.za

Mobile: 0834157466 by per cent body fat and steps per day. Multivariate analysis by gender (with per cent body fat as the dependent variable) suggested that males would have to increase the duration of vigorous exercise in order to reduce body fat, while females would benefit from sitting less, sleeping more, and increasing the duration of moderate exercise.

Conclusion and clinical relevance. In a self-selected sample involving motivated individuals, the SenseWear® armband provided information that would be useful in directing further research in women, focusing on sleeping pattern and moderately increasing activity levels.

\section{Introduction}

Over the past two decades there have been significant changes in employer attitudes towards promotion of workplace health, wellness and physical fitness. ${ }^{4}$ There is much evidence to support the economic and other benefits of worksite wellness programmes. 1,2,26,30 The benefits of these programmes include, among other spin-offs, improved productivity and worker morale, and reduction in absenteeism and staff turnover.

The prevalence of chronic diseases in the workplace has escalated to a large extent as a result of poor lifestyle habits. ${ }^{10,27,29}$ To effectively intervene, knowledge of lifestyle and factors affecting health must be known, e.g. physical activity levels, risk factors for chronic diseases, nutritional patterns and levels of stress. The monitoring of activity levels and total energy expenditure (TEE) of daily activities has become more important in order to have an impact on chronic disease prevention and management. ${ }^{18}$ Physical activity measurement is not only health promotional in that it creates awareness for individuals involved in exercise programmes, but is also prescriptive in terms of quantifying the required exercise 'dose'. ${ }^{13}$ Physical activity is therefore one of the cornerstones of any lifestyle management programme; however, the measurement of energy expenditure and physical activity levels has not always being accurate or objective. Such measurement has become much easier with a recently developed device for the assessment of TEE and physical activity levels (Body Media SenseWear Pro Armband $\left({ }^{\circledR}\right.$ ). The accuracy of the device has been confirmed and corroborated by Jakicic et al. ${ }^{16}$ and Malavolti et al. ${ }^{21,22}$ With advances in the standardisation of surveillance methodology and the introduction of more objective measures of physical activity energy expenditure and inactivity, ${ }^{36}$ the relationships between physical activity, inactivity, fitness and the prevalence of chronic diseases have become better understood. 5,6,9,35

The study presented here was designed to accurately measure the components of, and contributors to, daily energy expenditure in a cohort of corporate white-collar workers who had previously been 


\begin{tabular}{|c|c|c|c|}
\hline Parameters & $\begin{array}{l}\text { Females } \\
\text { Mean(SD) } \\
N=35\end{array}$ & $\begin{array}{l}\text { Males } \\
\text { Mean(SD) } \\
N=14\end{array}$ & $\begin{array}{l}\text { Difference } \\
\text { ( } p \text { values) }\end{array}$ \\
\hline Age (yrs) & $33.3(6.3)$ & $30.7(3.5)$ & 0.07 \\
\hline Mass (kg) & $78.6(22.4)$ & $84.8(15.8)$ & 0.28 \\
\hline Height (cm) & $162(6)$ & $178(7)$ & $<0.0001$ \\
\hline $\mathrm{BMI}\left(\mathrm{m}^{2} / \mathrm{kg}\right)$ & $29.4(7.3)$ & $27.1(4.2)$ & 0.16 \\
\hline Waist (cm) & $83.9(14.9)$ & $89.9(11.3)$ & 0.13 \\
\hline Hip (cm) & $110.2(15.1)$ & $101.2(7.9)$ & $<0.01$ \\
\hline Waist:hip ratio & $0.76(0.08)$ & $0.88(0.1)$ & $<0.01$ \\
\hline$\%$ Body fat & $28.9(8.5)$ & $19.4(8.4)$ & 0.002 \\
\hline
\end{tabular}

assessed as having $\geq 2$ risk factors for chronic disease by means of an in-house risk assessment process. The employer had expressed an interest in knowing how many at-risk employees would act on the information, and the researchers had an interest in utilising the information gained from a range of assessments in order to develop innovative health and wellness interventions for implementation within and/or outside the workplace.

\section{Methods}

This study was part of a larger study in which 122 'at-risk' employees of a medium-sized corporate entity in the financial services sector were invited to participate in a 6-month programme that involved physical assessments and personalised weight and activity management plans. These employees were a sub-set of a group of 621 that had previously participated in an in-house health and wellness assessment that was mainly based on medical and lifestyle history (e.g. hypertension, diabetes, hyperlipidaemia, cigarette smoking, alcohol consumption, poor diet and psychosocial stress). All of the 122 invitees had $\geq 2$ risk factors. Those who chose to participate underwent basic physical and medical assessment (height, weight, blood pressure, blood glucose and cholesterol, bicycle ergometry), and a number of anthropometric assessments. Skinfold thickness (triceps, supra-iliac and mid-thigh) was measured to the nearest millimetre using the Lange skinfold calliper and results were utilised to calculate percentage body fat. ${ }^{14}$ Waist and hip circumferences were measured using a plastic dressmaker's tape ${ }^{20}$ and the waist-to-hip ratio was calculated. The body mass index (BMI) was calculated using the measurements of height and weight according to the Bray formula. ${ }^{7}$ Predicted maximum oxygen uptake $\left(\mathrm{VO}_{2 \max }\right)$ was estimated using the YMCA protocol. ${ }^{11}$ Standardised testing procedures were followed as defined in the American College of Sports Medicine (ACSM) Guidelines. ${ }^{3}$

All participants were asked to consider wearing a Body Media SenseWear Pro Armband ${ }^{\circledR}$ to supplement and complement the other measures. This device was used to measure TEE and its parameters, and was worn on the triceps of the right arm for an average of 18 hours per day for a period of 6 days. The multi-sensor armband is worn continuously for a defined period of time in order to quantify metabolic physical activity and calculate energy expenditure in free-living individuals. Physiological body signals are gathered from five sensors (for measurement of skin temperature, near body temperature/heat flux, galvanic skin resistance, and accelerometry). Sophisticated software accumulates and translates the data into energy expenditure and activity-recognition patterns in order to calculate energy consumption based on predetermined algorithms. Parameters measured and calculated by the device include total (daily) energy expenditure (expended kilocalories), duration and quantification of physical activity, METS (metabolic equivalents expressed as $\mathrm{kcal} / \mathrm{kg} / \mathrm{hour}$ ), active energy expenditure (AEE), number of steps per day, body position recording, i.e. standing, sitting $v$. supine and sleeping. ${ }^{21}$ By convention, the physical activity levels were set to record above the sedentary threshold (3.0 METS) which is equivalent to a light moderate walk. The sedentary classification was between 0 and 3 METS, while at the other extreme, the vigorous and very vigorous METS classifications were at $6-9$ and $>9$ METS respectively.

Descriptive and inferential statistical methods mere used to analyse the data within and between genders. Variances were shown by the calculation of the means and standard deviations. Relationships were determined using multivariate analyses. Statistical significance was set at $p \leq 0.05$. All analyses were performed using the TexaSoft SDA version 6 Professional Edition package.

The study was approved by the institutional Committee for Research on Human Subjects. All subjects signed informed consent.

\section{Results}

Only $53(43 \%)$ of the 122 employees with identified health risks signed consent to participate in the 6-month project. Unfortunately

TABLE II. Daily metabolic and activity characteristics of the group $(N=49)$

\begin{tabular}{|c|c|c|c|}
\hline & $\begin{array}{l}\text { Females } \\
\text { Mean(SD) } \\
N=35\end{array}$ & $\begin{array}{l}\text { Males } \\
\text { Mean(SD) } \\
N=14\end{array}$ & $\begin{array}{l}\text { Difference } \\
\text { ( } p \text { values) }\end{array}$ \\
\hline Total energy expenditure (kcal/day) & $1974(271)$ & $2552(581)$ & 0.003 \\
\hline METS (kcal. $\mathrm{kg}^{-1} \cdot \mathrm{hr}^{-1}$ ) & $1.37(0.5)$ & $1.64(0.5)$ & 0.10 \\
\hline Active energy expenditure (kcal/day) & $364(243)$ & $704(405)$ & $<0.01$ \\
\hline Physical activity duration (min) & $69(49)$ & 101(61) & 0.1 \\
\hline Moderate exercise (min) (3 - 6 METS) & $62(40.4)$ & $92(47)$ & 0.045 \\
\hline Vigorous exercise (min) (6 - 9 METS) & $8.4(6.4)$ & $15.1(13.9)$ & 0.1 \\
\hline Very vigorous exercise $(\mathrm{min})$ ( $\geq 9 \mathrm{METS}$ ) & $4.9(5.5)$ & $8.5(7.8)$ & 0.13 \\
\hline Predicted $\mathrm{VO}_{2 \max }\left(\mathrm{ml} \cdot \mathrm{kg}^{-1} \cdot \mathrm{min}^{-1}\right)$ & $22(6.6)$ & $35(11.7)$ & $<0.001$ \\
\hline Steps (no.) & 5 914(2 058) & $8141(3200)$ & 0.03 \\
\hline Sedentary (min) & $1054(126)$ & $1147(389)$ & 0.9 \\
\hline Sleeping (min) & $331(82)$ & 292(61) & 0.08 \\
\hline
\end{tabular}


TABLE III. Correlations between active energy expenditure, METS, physical activity duration and body mass index

\begin{tabular}{lcc}
\hline Correlations & $\mathbf{R}^{\mathbf{2}}$ & $\boldsymbol{p}$ value \\
$\begin{array}{l}\text { Active energy } \\
\text { expenditure/METS v. } \\
\text { physical activity duration }\end{array}$ & $0.94 / 0.85$ & $<0.0001$ \\
$\begin{array}{l}\text { Active energy expenditure } \\
\text { v. body mass index }\end{array}$ & -0.58 & $<0.0001$ \\
$\begin{array}{l}\text { Physical activity duration } \\
\text { v. body mass index }\end{array}$ & -0.71 & $<0.0001$ \\
\hline
\end{tabular}

the employer resisted efforts to obtain information from those who declined the invitation to participate, but it is likely that the nonparticipants included some employees who had elected to pursue health-promoting activities outside the workplace, as well as others who had chosen to ignore their assessed risk status. Forty-nine of the 53 volunteered to wear the armbands, and this component was carried out during the first few weeks of the overall study. As such it is likely that participants' enthusiasm for the project and motivational levels were still high. Thirty-five subjects were female and 14 male. Table I represents the morphological characteristics of the participants. Men were significantly taller than women, had narrower hips, lower percentage body fat and higher waist:hip ratios than women. These findings are in line with expected differences between genders; however, it should be noted that average BMI and percentage body fat were in the overweight range for men and bordering on obese for women. ${ }^{12}$

The metabolic and activity characteristics of the study population are shown in Table II, and again the results are largely as expected. Women expended less energy than men (walked and exercised less), and as a consequence thereof demonstrated significantly lower TEE, AEE and predicted $\mathrm{VO}_{2}$ max. Most likely because of the relatively small sample size, the inter-gender difference in METS did not reach significance. Differences in vigorous and very vigorous exercise were also not significant because of the relatively small number of subjects in both groups who engaged in the higher levels of exercise.

Table III shows that for the total group, AEE and/or METS correlate best with duration of exercise in this study, not with intensity, potentially an important point in devising strategies for further intervention. Results also showed an inverse relationship between BMI and both duration of physical activity and AEE. The latter correlations introduce the question of cause and effect, i.e. do overweight subjects exercise less and consequently have lower measures of activity, or is a higher BMI simply the result of less physical activity?

In a stepwise regression analysis for the total group, $77 \%$ of the variance in MET levels was accounted for by percentage body fat $(p<0.001)$ and the number of steps taken daily $(p<0.006)$, with none of the other parameters reaching statistical significance. Further analysis was then mainly directed towards interrogating relationships with the percentage of body fat. In females, $70 \%$ of the variance in percentage body fat was accounted for by moderate exercise $(p<0.001)$, time spent sitting down $(p<0.049)$, and time spent sleeping $(p<0.001)$. Notably, the latter correlation was negative, i.e. the less time spent sleeping, the higher the percentage body fat. The same analysis in the group of males showed only a significant relationship between very vigorous exercise and percentage body fat (accounting for $56 \%$ of the variance).

\section{Discussion}

The first point to be noted is the at-risk employees' relatively low uptake of the offer to pursue the finding that they were candidates for long-term consequences of medical or lifestyle diseases. As already stated, the employer was reluctant to permit further interrogation of this point, so it is not clear how many of the non-responders had actually taken note of their risk status and how many had chosen to ignore it. As for the employees who chose to take action on the basis of their risk status, one must accept that they represent a small and biased sample, and any recommendations that are made can therefore only apply to and be tested on similar subjects. Noting this fact, both males and females in this study had BMI and percentage body fat values that were categorised as overweight, with the females' scores bordering on obesity $(29.4 \pm 7.3)$. In a classification of disease risk based on BMI (25.0-29.9), both sexes in this study are at increased risk for chronic conditions such as diabetes, hypertension, and cardiovascular disease. ${ }^{17}$ Overweight women carry greater risk for cardiovascular disease than those with normal body mass indices. ${ }^{32}$ Pedesen has indicated that chronic disease and premature mortality are not only related to obesity, but also to physical inactivity. ${ }^{25}$ It is therefore also important to explore activity and energy relationships, because regular physical activity has healthpromoting effects that go beyond the effects on weight control. In an at-risk group such as the one in this study, development of an exercise and/or lifestyle intervention programme may retard or reduce the risk of long-term consequences. ${ }^{23,24,33}$

The ability to accurately measure energy expenditure in free-living individuals is always a challenge; however, with the introduction of the SenseWear ${ }^{\circledR}$ armband, which is a non-invasive device that accurately captures physiological body signals, data can subsequently be downloaded to provide information on lifestyle, physical activity patterns, and movement and sleep profiles. The current study measured TEE, AEE, METS, number of steps per day, physical activity intensity and duration, and time spent sitting and lying/sleeping. Results showed that TEE was significantly higher in males (2 $552 \mathrm{kcal} /$ day) compared with females (1 $974 \mathrm{kcal} /$ day). Resting metabolic rate represents the amount of energy expended under resting conditions and typically accounts for about $60-70 \%$ of TEE. ${ }^{18}$ The thermic effect of food represents $\pm 10 \%$ of TEE, while the physical activity energy expended forms the third component of TEE. ${ }^{18}$ This latter component is most variable, as individuals choose to be active or not. The resulting effect of physical activity may therefore be small or can contribute significantly towards TEE. ${ }^{18,28}$ In the present study AEE represented $18.4 \%$ of TEE in females and $27.6 \%$ in males $(p<0.001)$, with the difference coming mainly from the greater number of steps taken by males per day (8 141 v. 5 914) and the greater duration of moderate exercise (92 v. 62 minutes/day). These latter figures for daily exercise are relatively high, perhaps explained by the fact that we were measuring during the early part of the project while gym attendance and adherence to the programme were at optimal levels.

The average sedentary person expends between 300 and 800 calories per day in physical activity from informal, unplanned types of movement to more structured exercise programmes. This may vary from person to person and according to differences in body mass. Jakicic et al. ${ }^{15}$ indicated that increasing exercise duration to 200 - 300 minutes per week facilitates long-term maintenance of weight loss. The ACSM and the American Heart Association (AHA) have recently revised the exercise guidelines for optimal health, concluding that exercise should be done at a moderate to high intensity for $3-5$ days of the week in order to derive greatest benefit. ${ }^{12}$ In this study the intensity of activity was lower in females as compared with males, and active energy expenditure and METS correlated better with duration of exercise than with intensity.

METS are calculated and averaged over a 24-hour period as an index of an individual's metabolic 'intensity', i.e. whether the person is moderately active or lives life at a slow pace. In the present study the MET levels for men and women were 1.64 and $1.37 \mathrm{kcal} / \mathrm{kg} /$ $\mathrm{h}$ respectively. Lifestyles with MET levels between 1.0 and 1.5 are considered to be predominantly sedentary, while values ranging 
between 1.51 and 2.0 are typically regarded as representing light to moderate activity. ${ }^{18}$ It would appear that the activity of the females in this study should be increased in intensity to at least moderate levels, thereby affording greater physiological benefits. The predicted oxygen consumption $\left(\mathrm{VO}_{2 \max }\right)$ for females further illustrates that the intensity of physical activity is low for the females $(22 \mathrm{ml} / \mathrm{kg} / \mathrm{min})$ as compared with the males $(35 \mathrm{ml} / \mathrm{kg} / \mathrm{min})$.

Results also showed an inverse relationship between BMI and both duration of physical activity and AEE. As already stated, the latter correlations lead one to at least consider the question of what is cause and what is effect, i.e. do overweight subjects exercise less and consequently have lower measures of activity, or is a higher BMI simply the result of less physical activity? Jakicic et al. believe that it is important to know how much exercise is required to retard unhealthy weight gain in adults. ${ }^{17}$ Observational evidence shows that in order to prevent weight gain, physical activity must be moderate to vigorous in intensity, and this intensity will also confer an increased fitness. ${ }^{12,16}$ The body of evidence therefore appears to support the notion that the BMI follows the level of activity, rather than the converse and, in fact, in attempts to motivate participants to lose weight in this particular study, discussions took place at personal and group level that were focused on the usual triad of eating less, a healthier diet, and more physical activity. Factors determining MET levels were interrogated for males and females, and analysis showed that percentage body fat was significantly correlated. For males in this study it appeared that body fat would respond best to vigorous exercise, but it should be noted that the males were already at moderate levels of activity, so this result is as expected. For females, however, there was an inverse relationship between body fat and increasing levels of activity and/or reduction of inactivity (spending less time sitting, sleeping more and increasing the amount or duration of moderate exercise). Telford (2007) believes that physical activity and cardiorespiratory fitness may improve energy balance and prevent obesity, reducing risk for chronic disease. ${ }^{34}$ It has been further shown that regular exercise induces favourable metabolic changes in muscle and adipose tissue, thereby promoting the use of fat for energy as opposed to storing it. ${ }^{18}$

In terms of the finding of the inverse relationship between percentage of body fat and time spent sleeping, females in this study slept for an average of $5 \frac{1}{2}$ hours per 24 hours. A recent study by Chaput et al. proposed an optimal relationship between sleep duration and regulation of body weight, with the ideal sleep duration around 7 - 8 hours. ${ }^{8}$ The researchers noted that short sleep duration predicts an increased risk of being overweight or obese, and that this is related to reduced circulating leptin levels relative to what is predicted by fat mass. Sleep duration is a modifiable risk factor, hence these findings may be of importance to the clinical management and treatment of obesity. Ko et al. (2007) would likely concur since they showed an association between obesity, reduced sleeping hours (and long working hours) in Chinese workers. ${ }^{19}$ While the body of evidence is accumulating in favour of this counter-intuitive finding, more research is probably required in order to determine the mechanisms responsible for this clinical phenomenon and the role of sleep management in the treatment of overweight and obesity. Meanwhile it is the intention of the researchers involved in the study presented here to follow up with an intervention that is targeted at overweight females and based on the results presented above. The intervention will focus less on modification of diet, and more on sitting less each day, walking more, and either going to bed earlier or waking later each day.

\section{Conclusion}

As with many corporate health and wellness programmes, many employees with risk factors for chronic disease do not avail themselves of remedial opportunities. In this study, participants whose physical, metabolic and activity parameters were measured were shown to be in the overweight to obese range. Men were more active than women. A potentially exciting weight reduction intervention was identified for women that would involve a moderate increase in activity and slight increase in the duration of sleep per night.

\section{REFERENCES}

1. Aldana SG, Greenlaw RL, Diehl HA, Salberg A, Merrill RM, Ohmine S. The effects of a worksite chronic disease prevention program. J Occup Environ Med 2005; 47: 558-64.

2. Aldana SG, Merrill RM, Price K, Hardy A, Hager R. Financial impact of a comprehensive multisite workplace health promotion program. Prev Med 2005; 40: 131-37.

3. American College of Sports Medicine. Guidelines for Exercise Testing and Prescription. 7th ed. Philadelphia: Lippincott Williams and Wilkins, 2006.

4. Atlantis E, Chow C-M, Kirby A, Fiatarone, Singh MA. Worksite intervention effects on physical health: a randomized controlled trial. Health Promot Int 2006; 21(3):191-200.

5. Blair SN, Cheng Y, Holder JS. Is physical activity or physical fitness more important in defining health benefits? Med Sci Sports Exerc 2001; 33(6 Suppl):S379-99; discussion S419-20.

6. Bouchard C. Physical activity and health: Introduction to the dose-response symposium. Med Sci Sports Exerc 2001; 33(6): 347-50.

7. Bray CA. Obesity: Definition, diagnosis and disadvantages. Med J Aust 1985;142: $52-5$

8. Chaput J-P, Despres J-P, Bouchard C, Trembley A. Sleep duration is associated with reduced leptin levels and increased adiposity: Results from the Quebec Family Study. Obesity 2007;15(1): 253-61.

9. Ekelund U, Franks PW, Sharp S, Brage S, Wareham NJ. Increase in physical activity energy expenditure is associated with reduced metabolic risk independent of change in fatness and fitness. Diabetes Care 2007; 30(8): 2101-6. Epub 2007 May 29.

10. Goetzel RZ, Anderson DR, Whitmer RW, Ozminkowski RJ, Dunn RL, Wasserman J. The relationship between modifiable health risks and health care expenditures. An analysis of the multi-employer HERO health risk and cost database. J Occup Environ Med 1998; 40: 843-54.

11. Golding LA, Myers CR, Sinning WE, eds. Y's way to Physical Fitness, 3rd ed. Champaign, Illinois: Human Kinetics, 1989

12. Haskell WL, Lee IM, Pate RR, et al. Physical activity and public health: Updated recommendations for adults from the American College of Sports Medicine and the American Heart Association. Med Sci Sports Exerc 2007; 39(8):1423-34.

13. Heyward VH. Principles of Assessment, Prescription and Exercise Programme Adherence in Advanced Fitness Assessment and Exercise Prescription. Champaign, Illinois: Human Kinetics, 2006.

14. Jackson AS, Pollock ML. Research progress in validation of clinical methods of assessing body composition. Med Sci Sports Exerc 1984;16(6): 606-15.

15. Jakicic JM. The role of physical activity in the prevention and treatment of body weight gain in adults. J Nutr 2002;132: 3826S-29S.

16. Jakicic JM, Marcus M, Gallacher K I, et al. Evaluation of the SenseWear Pro Armband to assess energy expenditure during exercise. Med $\mathrm{Sci}$ Sports Exerc 2004; 36(5): 897-904.

17. Jakicic M, Clark R, Coleman E, et al. American College of Sports Medicine's position stand: Appropriate intervention strategies for weight loss and prevention of weight regain for adults. Med Sci Sports Exerc 2001; 33: $2145-56$

18. Kiem NL, Blanton CA, Kretsch MJ. America's obesity epidemic: measuring physical activity to promote active lifestyles. J Am Diet Assoc 2004; 104:1398-409.

19. Ko GTC, Chan JCN, Wong PTS, et al. Association between sleeping hours, working hours and obesity in Hong Kong Chinese: The 'better health for better Hong Kong' health promotion campaign. Int $\mathrm{J}$ Obesity 2007: 31: 254-60.

20. Lohman TG, Roche AF, Martoveli R, eds. Anthropometric Standardization Reference Manual. Champaign, Illinois: Human Kinetics, 1988.

21. Malavolti M, Pietrobelli A, Dugoni M, et al. A new device for measuring resting energy expenditure (REE) in healthy subjects. Nutr Metab Cardiovasc Dis 2007; 17(5): 338-43.

22. Malavolti M, Pietrobelli A, Dugoni M, et al. A new device for measuring daily total energy expenditure (TEE) in free living individuals. Int $J$ Body Comp Res 2005; 3: 63. 
23. Melanson KJ, Mclnnis KJ, Rippe JM, Blackburn G, Wilson PF. Obesity and cardiovascular disease risk: research update. Cardiol Rev 2001; 9(4): 202-7

24. Nguyen HQ, Ackermann RT, Berke EM, et al. Impact of a managed-medicare physical activity benefit on health care utilization and costs in older adults with diabetes. Diabetes Care 2007; 30: 43-8.

25. Pedesen BK. Body mass index: an independent effect of fitness and physical activity for all cause mortality. Scand J Med Sci Sports 2007. 17(3); 196-204

26. Pelletier KR. A review and analysis of the clinical and cost-effectiveness studies of comprehensive health promotion and disease management programs at the worksite: update VI 2000-2004. J Occup Environ Med 2005; 47: 1051-58.

27. Pelletier B, Boles M, Lynch W. Change in health risks and work productivity over time. J Occup Environ Med 2004; 46: 746-54.

28. Ravussin E, Bogardus C. A brief overview of human energy metabolism and its relationship to essential obesity. Am J Clin Nutr 1992; 55: 242S$45 \mathrm{~S}$

29. Rodgers A, Ezzati M, Van der Hoorn S, Lopez AD, Ruey-Bin L, Murray CJL. Comparative Risk Assessment Collaborating Group. Distribution of Major Health Risks: Findings from the Global Burden of Disease Study. 2004; PLoS Med 1(1): e27.
30. Serxner SA, Gold DB, Grossmeier JJ, Anderson DR. The relationship be tween health promotion program participation and medical costs: a dose response. J Occup Environ Med 2003; 45: 1196-200.

31. Shephard RJ. A critical analysis of worksite fitness programmes and their postulated economic benefits. Med Sci Sports Exerc 1992; 24; 354-70.

32. Song Y, Manson JE, Meigs JB, Ridker PM, Buring JE, Liu S. Comparison of usefulness of body mass index versus metabolic risk factors in predicting 10-year risk of cardiovascular events in women. Am J Cardiol 2007; 100(11): 1654-8

33. Stein AD, Shakour SK, Zuidema RA. Financial incentives, participation in employer-sponsored health promotion, and changes in employee health and productivity: HealthPlus Health Quotient Program. J Occup Environ Med 2000; 42: 1148-55.

34. Telford RD. Low physical activity and obesity: causes of chronic disease or simply predictors? Med Sci Sports Exerc 2007; 39(8):1233-40.

35. Wang G, Pratt M, Macera CA, Zheng ZJ, Heath G. Physical activity, cardiovascular disease, and medical expenditures in US adults. Ann Behav Med 2004; 28(2): 88-94.

36. Wareham NJ, Rennie KL. The assessment of physical activity in individuals and populations: why try to be more precise about how physical activity is assessed? Int J Obes Relat Metab Disord 1998; Suppl (2): S30-8.

\title{
Incremental exercise test performance with and without a respiratory gas collection system
}

\author{
James R Clark (BSc (Hons), (BA (Hons)) \\ Institute for Sport Research, Department of Biokinetics, Sport and Leisure Sciences, University of Pretoria
}

\begin{abstract}
Objective. Despite their widespread use in exercise testing, few data are available on the effect of wearing respiratory gas collection (RGC) systems on exercise test performance. Industrial-type mask wear is thought to impair exercise performance through increased respiratory dead space, flow resistance and/or discomfort when compared with RGC facemasks, but whether performance decrements exist for RGC facemask wear versus non-wear is unclear. The objective of this study was to evaluate the difference in incremental exercise test performance with and without a RGC system.
\end{abstract}

\section{CORRESPONDENCE:}

James R Clark

Institute for Sport Research

LC de Villiers Sport Centre

University of Pretoria

0002 Pretoria

South Africa

Tel: +27 124206033

Fax: +27 124206099

E-mail: jimmy.clark@up.ac.za
Design. Twenty moderately active males (age $21.0 \pm 1.9$ years; $V^{2 \text { peak }} 55.9 \pm 3.0 \mathrm{ml} \cdot \mathrm{kg}^{-1} \cdot \mathrm{min}^{-1}$ ) performed two progressive treadmill tests to volitional exhaustion. In random order subjects ran with (MASK) or without (NO-MASK) a RGC facemask and flow sensor connected to a gas analyzer. Descriptive data (mean \pm SD) were determined for all parameters. The Wilcoxon signed rank test for paired differences was used to assess mean differences between MASK and NO-MASK conditions.

Results. Exercise time to exhaustion, peak treadmill speed, peak blood lactate concentration, peak heart rate and rating of perceived exertion (RPE) were not different $(p>0.05)$ between MASK and NO-MASK conditions

Conclusions. Incremental exercise test performance is not adversely affected by RGC and analysis equipment, at least in short duration progressive treadmill exercise. Respiratory gas analysis during exercise testing for diagnostic, performance assessment or training prescription purposes would appear to be unaffected by RGC systems

\section{Introduction}

Exercise testing with respiratory gas collection (RGC) and analysis during indirect calorimetry has long been a routine procedure in exercise physiology laboratories, enabling the simultaneous measure- 